\title{
Preface by the CW2017 organizers including program, advisory board and photo
}

Cyrille De Saint Jean

Laboratoire d'Etudes de Physique, Saint Paul Lez Durance Cedex, France

Received: 13 August 2018

The fourth edition of the International Workshop on Nuclear Data Covariances, organized by CEA Cadarache and NEA, took place in Aix en Provence, France, October 26, 2017. This workshop is the continuation of the series of workshops held in Port Jefferson, USA (2008), Vienna, Austria (2011) and
Santa Fe, New Mexico, USA (2014). It was open to contributions on all aspects of nuclear data covariance evaluations, for all observables (e.g. cross sections, energy and angle spectra, fission yields, and resonance parameters) from the resonance region up to the high energy range, for light to heavy nuclei.

\begin{tabular}{|c|c|c|c|c|c|}
\hline & Monday $02 / 10$ & Tuesday $03 / 10$ & Wednesday 04/10 & Thursday 05/10 & Friday $06 / 10$ \\
\hline gh & \multirow{6}{*}{ Workshop Registration } & & & & \\
\hline $9 \mathrm{~h} 30$ & & D. Neudecker & D. Neudecker & V. Huy & $\begin{array}{l}\text { L. Volat } \\
\text { A. Rizzo }\end{array}$ \\
\hline $10 \mathrm{~h} 00$ & & J. Wang & Y. Danon & H. Iwamoto/A. Stankovskiy & \\
\hline $\begin{array}{l}\text { Coffee Break (10h30 - } \\
11 \mathrm{~h} 15)\end{array}$ & & & & & \\
\hline $11 \mathrm{~h} 15$ & & E. Bauqe & M. Kerveno & G. Shiba & J. Dyrda \\
\hline $11 \mathrm{~h} 45$ & & & M. Estienne & P. Leconte & L. Fiorito \\
\hline \multicolumn{6}{|l|}{ Lunch Break (12h15 - 14h) } \\
\hline & & & & & \\
\hline $14 \mathrm{~h}$ & Introd & M. White & G. Kessedilan & M. Auferio / A. Bidaud & id of the y \\
\hline $14 h 30$ & $\begin{array}{l}\text { Introductory Talk (M. } \\
\text { Salvatores) }\end{array}$ & E. Privas & $\begin{array}{l}\text { A. Chebboubi/S. Julien- } \\
\text { Lafferriere }\end{array}$ & j. Gaillet & \\
\hline $15 \mathrm{~h}$ & M. Munoz-Zuniga (IFPEN) & A. Sonzooni & C. Mattoon & H. Siostrand & \\
\hline \multicolumn{6}{|l|}{ Coffee Break (15h30 - 16h) } \\
\hline $16 \mathrm{~h}$ & p. Talou & R. Xu & 0 . Cabellos & I. Kodeli & \\
\hline $16 \mathrm{~h} 30$ & G. Arbanas & H. Leeb & L. Leal & S. Lahave & \\
\hline $17 \mathrm{~h}$ & D. Foliano & R. Capote & SG44 & SG44 & \\
\hline $17 \mathrm{~h} 30$ & Y. Bai & E. Bauge & SG44 & SG44 & \\
\hline $18 \mathrm{~h}$ & G. Noquere & 0. Litaize & SG44 & SG44 & \\
\hline \multicolumn{6}{|l|}{$18 \mathrm{~h} 30$} \\
\hline & & & & & \\
\hline & & & & & \\
\hline $\begin{array}{l}\text { Covariance Evaluation } \\
\text { Methodology }\end{array}$ & 15 & & & & \\
\hline \multicolumn{6}{|l|}{ Experimental Uncertainties 7} \\
\hline Nuclear Models & 3 & & & & \\
\hline Applied Covariances & 15 & & & & \\
\hline \multicolumn{6}{|l|}{ Nuclear Data Libraries } \\
\hline General talk & 3 & & & & \\
\hline & & & & & \\
\hline Total & 46 & & & & \\
\hline
\end{tabular}




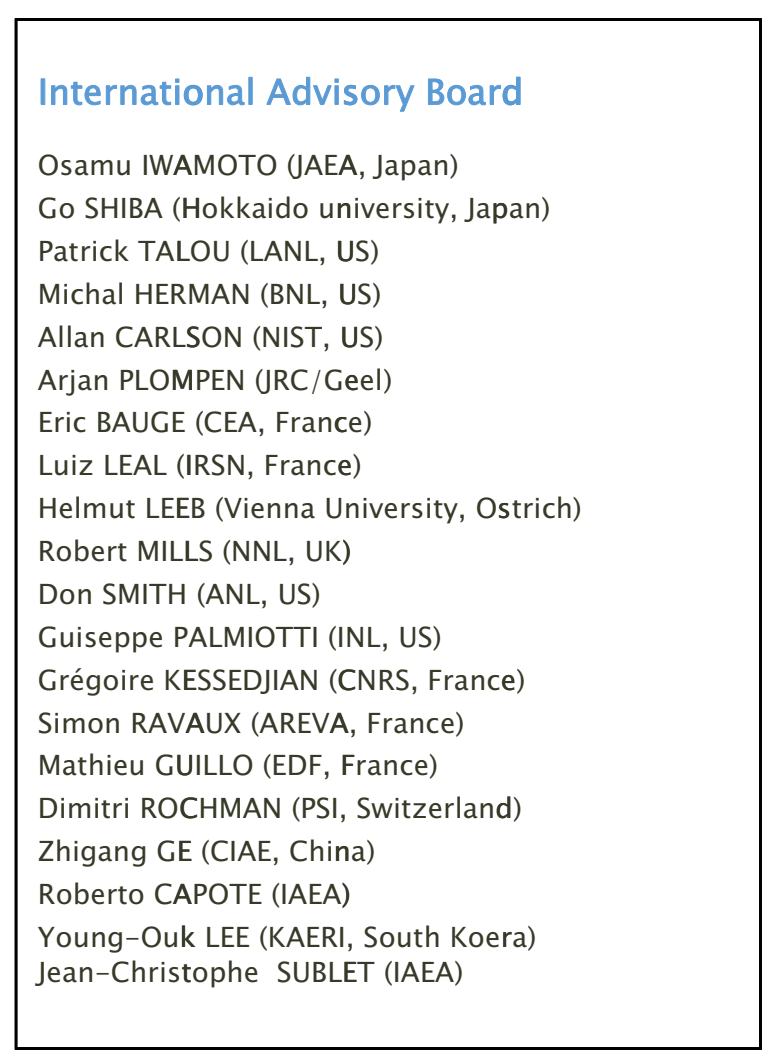

The main topics of the workshop were related to: - covariance evaluation methodology (15 talks),

- nuclear reaction models prior uncertainties and biases (3 talks),

- measurement breakthrough to evaluate and reduce systematic uncertainties as well as biases ( 7 talks),

- nuclear data libraries: status of their covariance files/ representation of covariance and formatting issues (3 talks), and

- applied covariances, from nuclear reaction model parameters to various applied parameters covariances (15 talks).

The number of participants was of about 50 people (for 45 oral presentations), coming from the United States, Europe, China, and Japan. Focused on the problem of uncertainties, this workshop had as main objective to open the future trends in the measurements, nuclear reaction modelling and in the process of nuclear data evaluation. The participation of national and international experts strongly contributed to its undeniable success.

After a general workshop introduction (C. De Saint Jean), an introductory talk was given by M. Salvatores to highlight the importance of nuclear data uncertainties for end-up users (reactors physicists). A last introductory talk, devoted to methods of uncertainties and correlations evaluation coming from other physic or mathematical

\begin{tabular}{|l|}
\hline \\
Local Organizing Committee \\
Pascal ARCHIER (CEA, France) \\
David BERNARD (CEA, France) \\
Olivier BOULAND (CEA, France) \\
Oscar CABELLOS (NEA,OECD) \\
Abdel CHEBBOUBI (CEA, France) \\
Cyrille DE SAINT JEAN (CEA, France) \\
Pierre LECONTE (CEA, France) \\
Olivier LITAIZE (CEA, France) \\
Franco MICHEL-SENDIS (NEA, OECD) \\
Gilles NOGUÈRE (CEA, France) \\
Olivier SEROT (CEA, France) \\
Pierre TAMAGNO (CEA, France) \\
\hline
\end{tabular}

domains, was then given by M. Munoz-Zuniga (IFPEN) on Bayesian approach for model calibration in the oil and gas management. In the previous conference (organized in 2014 to Santa-Fe), the intensive use of Monte Carlo methods to propagate nuclear data uncertainties towards the applications was particularly observed in various talks. The major trends and advances of this CW2017 conference were related to better treatment of experimental systematic uncertainties such as normalization, detector efficiencies, background reduction,... Various talks given by experimentalists have shown their recent solutions to minimize these kind of uncertainties. In addition, theoreticians and evaluators proposed various advances to better take into account prior nuclear reaction models uncertainties with possible solutions given by more fundamental theories (microscopic ingredients). At last, this workshop has reminded the importance of integral experiments used as validation experiments but sometimes also as part of a more direct evaluation of the nuclear data of interest.

We would like to express our gratitude to all participants for their presentations but also for the fruitful discussions that took place during the conference.

Cyrille De Saint Jean (Workshop Chair), on behalf of the CW2017 local organizing committee. 

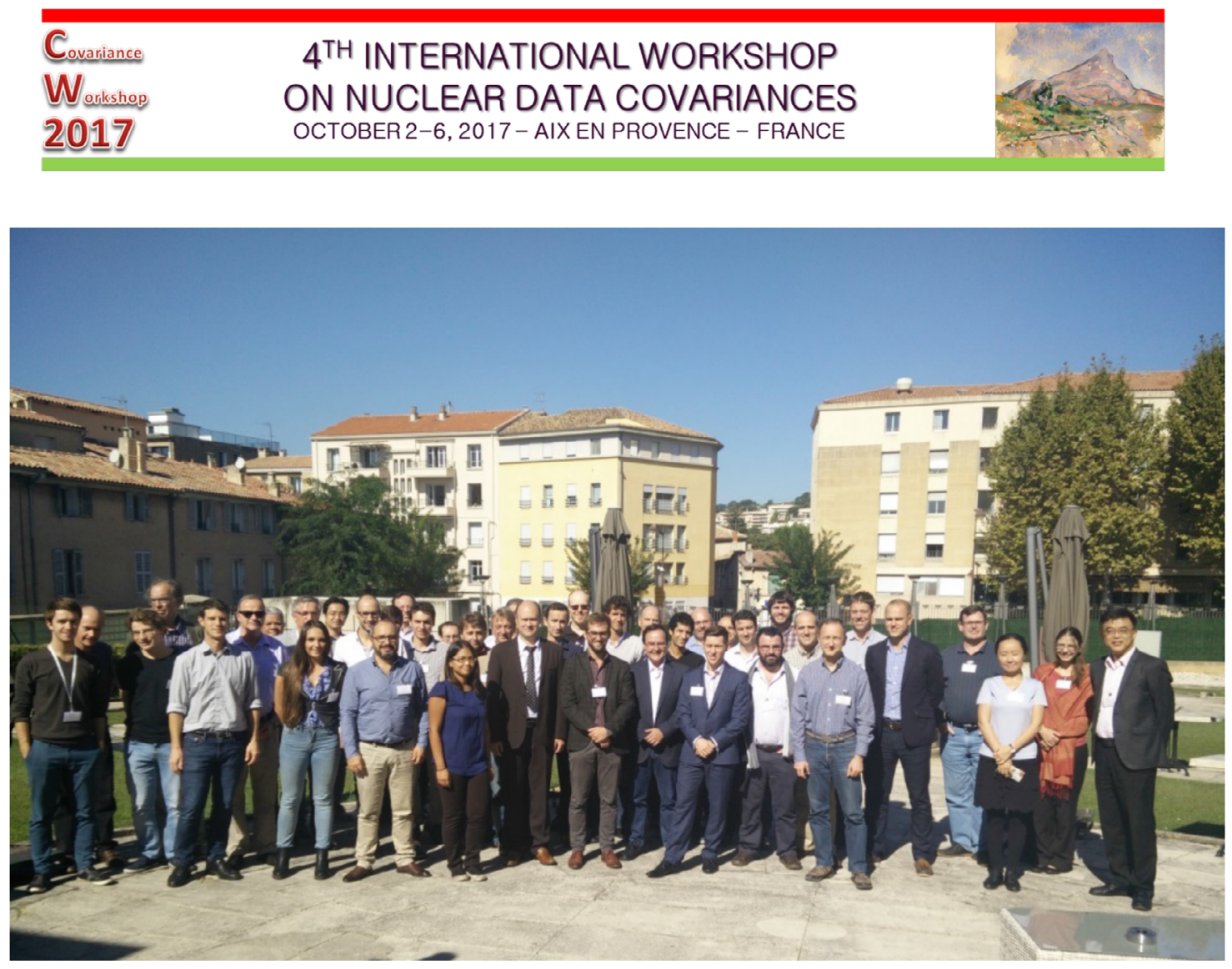